\title{
Opportunistic Sightings of Cetaceans in Nearshore and Offshore Waters of Southeast Florida
}

\author{
Denise L. Herzing ${ }^{1,2}$ and Cindy R. Elliser ${ }^{1,3}$ \\ ${ }^{1}$ The Wild Dolphin Project, P.O. Box 8436, Jupiter, FL 33468 \\ ${ }^{2}$ Department of Biological Sciences, Florida Atlantic University, 777 Glades Rd, \\ Boca Raton, FL 33431 \\ ${ }^{3}$ Pacific Mammal Research, 1513 A Ave, Anacortes, WA 98221 \\ Denise Herzing: dlherzing@wilddolphinproject.org
}

HERZING, D. L. and C. R. Elliser. Opportunistic Sightings of Cetaceans in Nearshore and Offshore Waters of Southeast Florida. J. Northw. Atl. Fish. Sci., 48: 21-31. doi:10.2960/J.v48.m709

\begin{abstract}
The majority of cetacean research pertaining to the western North Atlantic Ocean has focused on the waters between North Carolina in the United States and the Scotian Shelf in Canada; little is known about cetacean occurrence and distribution in the waters off southeast Florida (FL) where the subject study was conducted. Our study describes opportunistic, ship-based sightings of cetaceans during 1989-2006 in nearshore and offshore waters located in the Gulf Stream between the Bahamas and Palm Beach, FL. Nine species were observed during 60 sightings. For two of the documented species (false killer whale, Pseudorca crassidens, and Fraser's dolphins, Lagenodelphis hosei), very little existing information was available with respect to sightings and distribution in the study area. The other seven species were observed in waters south of their documented distributions, based on sightings data from dedicated surveys conducted along the US East Coast, but which only extended to central FL. We documented distinctive physical attributes of offshore ecotype bottlenose dolphins (Tursiops truncatus) and described foraging behavior of false killer whales. Our opportunistic observations highlight the importance of conducting regular surveys in this little-researched region. Data gathered during our study may have important implications for cetacean stock assessments and conservation strategies.
\end{abstract}

Keywords: cetaceans, sightings, bottlenose dolphin ecotypes, false killer whale, western North Atlantic Ocean, Florida, Gulf Stream.

\section{Introduction}

The ecology of pelagic tropical cetacean communities is largely unknown for most areas around the world (Mullin and Fulling, 2004). The distribution of marine mammals may be affected by environmental variables and their behavioral needs (e.g., foraging, mating, socializing), however, data pertaining to these factors for pelagic cetacean communities are hard to obtain due to the high mobility of the animals and the logistical difficulty of gathering data at sea (Schick et al., 2011). Thus, in some areas, very little information is known about cetacean populations. One such area is the offshore waters of southeast Florida (FL), which has very little cetacean survey coverage compared to other cetacean habitats in the western North Atlantic Ocean (Hamazaki, 2002; Jefferson and Schiro, 2008; Schick et al., 2011; Waring et al., 2015).

The majority of western North Atlantic cetacean surveys and research focus on the waters between North Carolina (NC) in the United States (US) and Nova Scotia in Canada (e.g., Hamazaki, 2002). Stock assessments are updated regularly (annually for "strategic stocks" and every three years, or when new information is available, for nonstrategic stocks) by the National Marine Fisheries Service (NMFS) for most cetacean species inhabiting the US East Coast, with the most recent Stock Assessment Reports (SARs) updated in 2014 (Waring et al., 2015). The SARs include data from many different studies covering various coastal and offshore areas, cetacean species, time frames (e.g., seasonal, annual) and methods (e.g., plane- vs. shipbased surveys), but dedicated surveys of the waters south of central FL are lacking. Even when considering data from the broad-based Ocean Biogeographic Information System - Spatial Ecological Analysis of Megavertebrate Populations (OBIS-SEAMAP) database (Halpin et al., 2009), cetacean surveys conducted south of Cape Hatteras, NC are relatively scarce (Mullin and Fulling, 2003; Garrison et al., 2010; Schick et al., 2011).

The waters off of southeast FL provide a different cetacean habitat compared to the waters north of Cape Hatteras, due to the influence of the Gulf Stream, which varies in width and proximity to shore along the US East Coast. The Gulf 
Stream is a strong, warm ocean current that originates in the Gulf of Mexico as the Florida Current, then flows along the southern tip of FL and northward until it is deflected northeasterly and further offshore at Cape Hatteras, NC (Groves and Hunt, 1980). Oceanic features, such as fronts and eddies, are often associated with the Gulf Stream and such features can produce ecological effects (e.g., on food web stability and phytoplankton production) that can affect animal abundance and distribution (Owen, 1981).

In the western North Atlantic, groupings of cetacean species have been classified by habitat use correlated with depth, temperature range and distance from the coast (Hamazaki, 2002; Schick et al., 2011). Moore (1953) reported the occurrence of 21 marine mammal species in FL waters and suggested that the Gulf Stream may induce some tropical species to visit FL waters and that the southward counter-current flow may be influential in bringing marine mammals from the north into FL waters. For example, the occurrence and distributions of sperm whales (Waring et al., 1993) and sea turtles (Hoffman and Fritts, 1982) have been associated with features of the Gulf Stream. The distribution of pelagic odontocetes in waters off the US East Coast, are also likely associated with the Gulf Stream, its distance from shore and associated fronts and eddies, as noted in the high biodiversity of species from northern and southern regions and coastal and pelagic habitats recorded during stranding events off Cape Hatteras, NC (Byrd et al., 2013). The location of the west wall of the Gulf Stream varies along the US East Coast, but is located closest to shore, $<16$ km (Gyory et al., 2013), in our study area off the southeast coast of FL (Fig. 1). Thus, cetacean abundance and distribution in southeast FL waters may differ from the more northern waters of the western North Atlantic due to the variations in the width of the Gulf Stream and its close proximity to shore. However, research on this topic is lacking in our study area.

Our study describes the cetaceans sighted opportunistically by staff from the Wild Dolphin Project (WDP) while crossing the Gulf Stream in southeastern FL waters en route to two study sites in the Bahamas. In addition, we describe in more detail, information from sightings of the bottlenose dolphin (Tursiops truncatus) and the false killer whale (Pseudorca crassidens). The bottlenose dolphin occurs as two ecotypes (Hersh and Duffield, 1990; Mead and Potter, 1995; Hoelzel et al., 1998; Torres et al., 2003). We describe the physical difference in appearance of the offshore ecotype compared to the coastal ecotype in our study area because this difference may also occur in other areas of the western North Atlantic. We also describe our observations of the foraging behavior of the false killer whale, which is primarily oceanic and has been

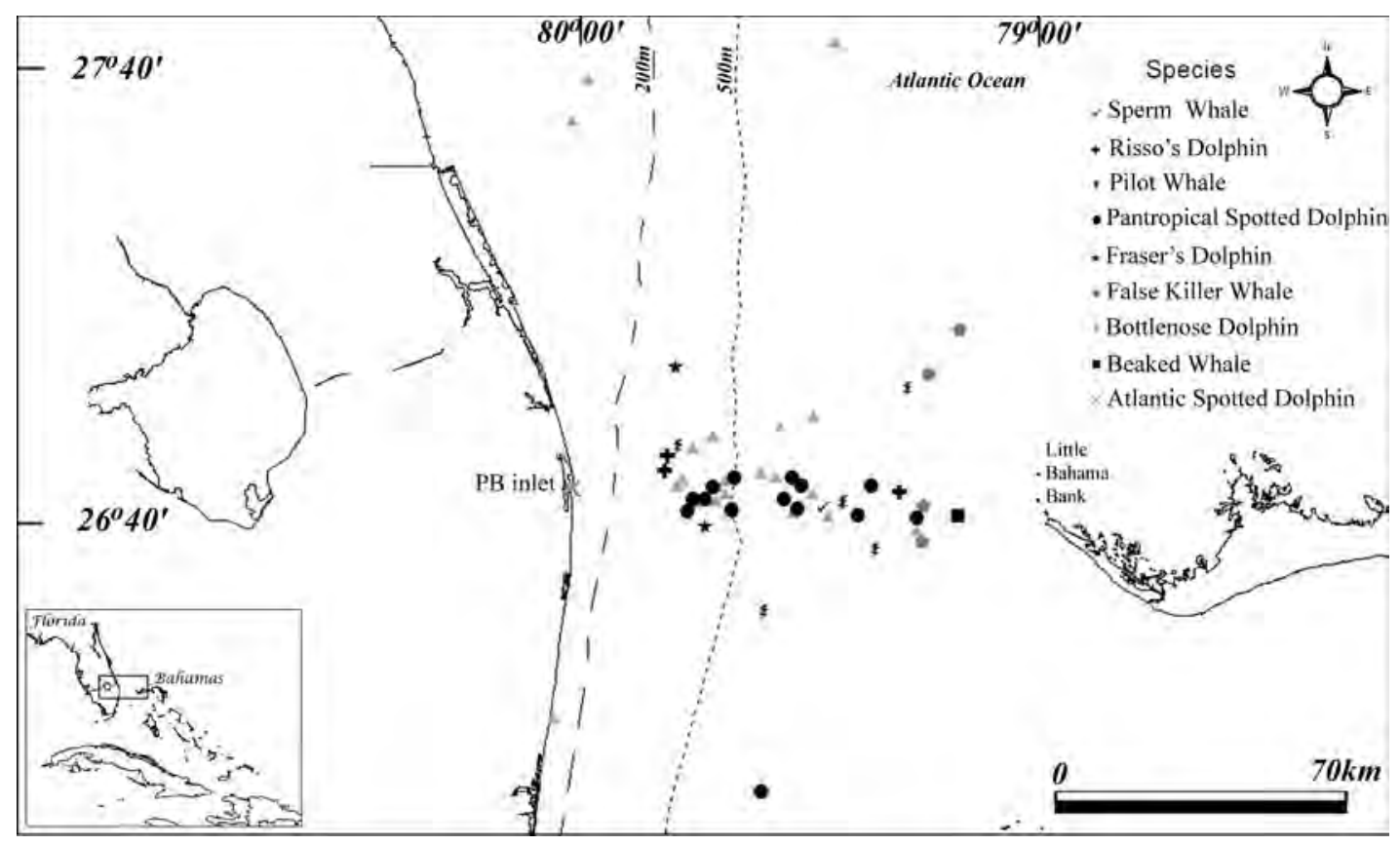

Fig. 1. Map of opportunistic cetacean sightings in nearshore and offshore waters of southeast Florida out to the western edge of Little Bahama Bank during 1989-2006. All Atlantic spotted dolphin sightings occurred near the Palm Beach Inlet, labeled "PB inlet" (the one marker on the map for these sightings is slightly obscured by a bottlenose dolphin sighting marker in the same area). The Gulf Stream flows northward along the US East Coast, close to shore in our study area and is located farther offshore as it flows north. 
sighted in the northern Gulf of Mexico (Maze-Foley and Mullin, 2006) and in the western North Atlantic from Cape Hatteras, NC to Tierra del Fuego, Argentina (Stacey et al., 1994). However, false killer whales have rarely been documented off the coast of FL (Waring et al, 2015) and sightings compiled in the OBIS-SEAMAP database, as of 2 May 2016, show only two sightings off northern FL (Garrison, 2013a; Halpin et al, 2009).

\section{Materials and Methods}

Since 1985, staff from WDP have studied a resident community of Atlantic spotted dolphins (Stenella frontalis) located on Little Bahama Bank (LBB) (Herzing, 1997; Elliser and Herzing, 2012; 2014). Every year during 1989-2006, WDP staff made regular trips (8-10 trips per year) during May through September between Palm Beach, FL and the primary study site on Little Bahama Bank (LBB) (Fig. 1), crossing the Gulf Stream aboard a 19 m catamaran research vessel. During 1998-2004, one trip per year was also made during January-March to a secondary study site and spotted dolphin community on Great Bahama Bank (GBB), south of LBB.

Trip durations lasted between 6 and 12 hours each way depending on weather and oceanic conditions. There were one to five observers (i.e., crew and volunteers) on watch for the duration of each trip. Observers watched for any cetacean activity by scanning ahead of the vessel across a $180^{\circ}$ radius, with the naked eye, during daylight hours (0700-1900) from a height of $23 \mathrm{ft}$ above the waterline. When observed, cetacean species were recorded by the crew and verified by scientific observers from WDP with expertise in cetacean identification. When a group or individual was observed, vessel speed was reduced to less than 7 knots, the boat's course was redirected from the planned route and the group was approached. The boat was slowly and carefully driven to within roughly $100 \mathrm{~m}$ of the group, being careful to avoid sudden turns, accelerations, decelerations, and approaching the group head-on or quickly from behind, following general NOAA viewing guidelines for the region (NOAA, 2012). The cetaceans were identified to the lowest taxonomic level that researchers were confident in assessing. Group size was recorded and photographs were taken of as many individuals of each group as possible (using various Canon film and digital cameras over the years). For every sighting, the goal was to obtain two to three photographs of each individual, however, this was not always possible due to weather conditions and behavior of the animals. Sightings also entailed ad libitum (Altman, 1974) descriptions of behavior which were categorized as either social, travel, foraging or unknown. Once documented, the captain resumed the boat's prior route towards either Little Bahama Bank or FL. The exception to this protocol occurred during a single occasion when the boat remained idle with a group of false killer whales while their behavior was documented and photographs were taken. After about two hours, we ended the sighting due to reduced light levels and time constraints.

\section{Results}

For each crossing, routes were $110^{\circ}$ ESE from the Palm Beach Inlet, covering a total estimated distance of $34360 \mathrm{~km}$ and 2084 hours of observation effort during the course of the study (Table 1). Roughly the same amount of sampling effort occurred on the return trips to FL from the Bahamas. A total of 60 opportunistic sightings of nine different types of cetaceans occurred, including eight species and a beaked whale only identifiable as a member of the Ziphiidae family (Table 2). Ranges for total group

Table 1. Estimated sampling effort, distance traveled $(\mathrm{km})$ and observer time (hrs), for opportunistic sightings of cetaceans off the southeast coast of Florida (Little Bahama Bank) during trips to Little Bahama Bank and Great Bahama Bank during 1989-2006 (May-September) and 1998-2004 (January-March), respectively. A crossing is defined as a oneway trip to or from FL to Little Bahama Bank or Great Bahama Bank.

\begin{tabular}{lcc}
\hline \multicolumn{1}{c}{ Sampling Effort } & FL to Little Bahama Bank & FL to Great Bahama Bank \\
\hline Average number of crossings per year & 18 & 2 \\
Average observer time per crossing (hrs) & 6 & 10 \\
Average observer time per year (hrs) & 108 & 20 \\
Distance per crossing (km) & 100 & 140 \\
& & 140 \\
Total observer time (all years, hrs) & 1944 & 1960 \\
Total distance traveled (all years, km) & 32400 & \\
\hline
\end{tabular}




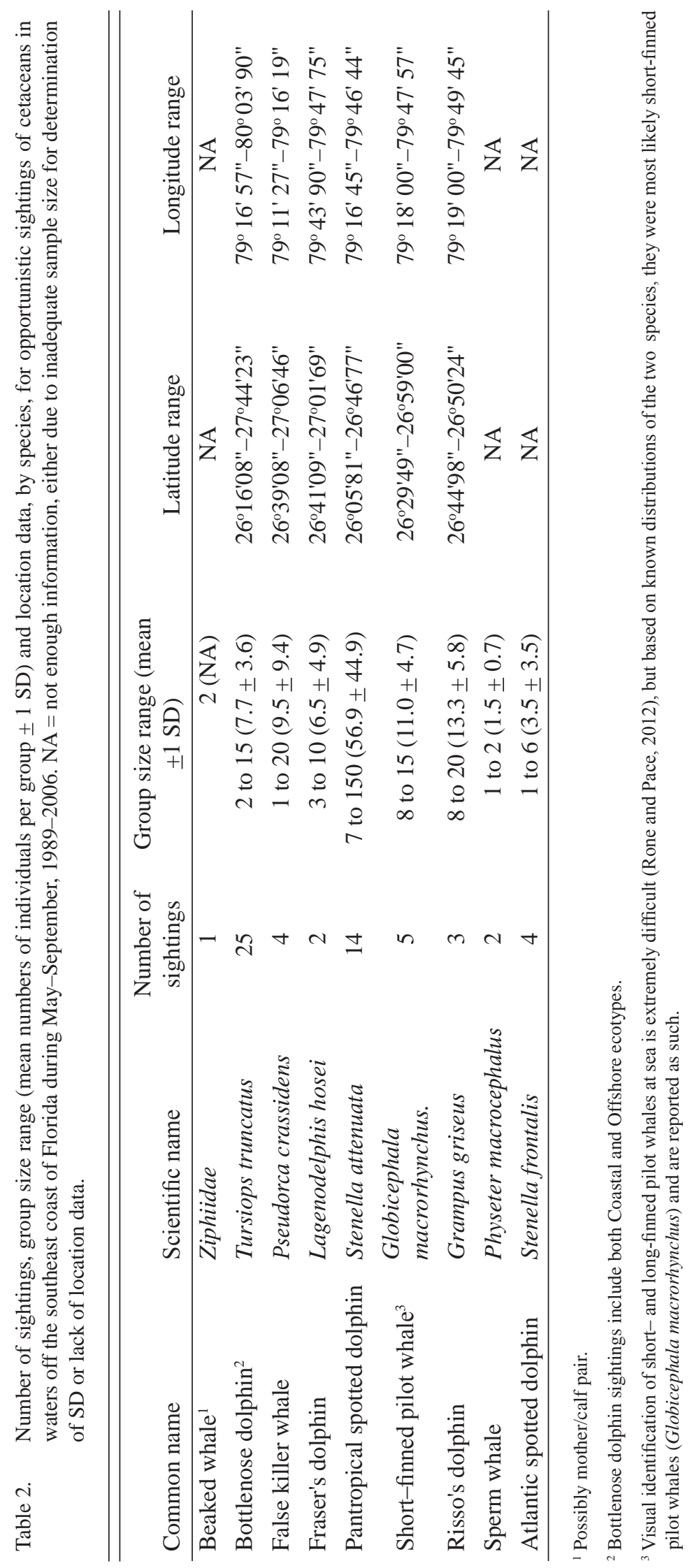


size (Table 2) should be viewed with caution because they may not be fully representative of the true group size variation for species with fewer than four sightings. Visual identification of short- and long-finned pilot whales at sea is extremely difficult (Rone and Pace, 2012), but based on known distributions of the two species, they were most likely short-finned (Globicephala macrorhynchus) and were reported as such. Bottlenose dolphin sightings included both coastal and offshore ecotypes.

Bottlenose dolphins were the most commonly sighted cetacean, followed by pantropical spotted dolphins. Only bottlenose dolphins, pantropical spotted dolphins (Stenella attenuata) and Risso's dolphins (Grampus griseus, seen twice on one day) were seen more than once in a given year. All sightings occurred during May-September, except for one sperm whale (Physeter macrocephalus) and one pantropical spotted dolphin sighting which each occurred during January of 1991 and 2001, respectively. The two sightings of Fraser's dolphins (Lagenodelphis hosei) occurred in July during 1991 and 1993 and the five pilot whale sightings occurred in either May or September during 1990-1992, 1995 and 1999. During all but one sighting, the documented behavior was travel; for one of the false killer whale sightings, the animals were foraging.

Fig. 1 shows the distribution of the cetacean sightings (excluding one sperm whale sighting due to lack of latitude/longitude data). Only two species were sighted shoreward of the $200 \mathrm{~m}$ isobath (i.e., on the continental shelf), the bottlenose dolphin and the Atlantic spotted dolphin. All Atlantic spotted dolphin sightings occurred near the Palm Beach Inlet. Fraser's dolphins were only seen at depths between $200 \mathrm{~m}$ and $500 \mathrm{~m}$. The bottlenose dolphin, Risso’s dolphin, pilot whale and pantropical spotted dolphin were seen in many different locations across the Gulf Stream, in waters east of and deeper than the $200 \mathrm{~m}$ isobath. The larger odontocetes, including the sperm whale, false killer whale and beaked whale, were only sighted at depths greater than $500 \mathrm{~m}$. Interestingly, false killer whales were only seen on the east side of the Gulf Stream, closer to Little Bahama Bank, north of Grand Bahama Island. Other than two sightings off northern FL (Garrison, 2013a), the only other false killer whale sightings near our study area were in waters east of the Abacos, Bahamas (Dunn, 2013b).

\section{Bottlenose dolphins: coastal vs. offshore ecotypes}

Definitive identification of bottlenose dolphin ecotype was not always possible. Four of the sightings were determined to be offshore ecotype bottlenose dolphins, sighted east of $79^{\circ} 46^{\prime} 00^{\prime \prime}$ at $26,52,56$ and $75 \mathrm{~km}$ from the FL coast near the 500-600 $\mathrm{m}$ isobath. These bottlenose dolphins were distinctively larger in size and very robust as compared to the coastal ecotype, the latter which can easily be identified from a boat. Many, if not all, of the offshore ecotype bottlenose dolphins that we saw had a unique feature; a characteristic white saddle mark on the peduncle posterior to the dorsal fin. A coastal ecotype bottlenose dolphin (with no white saddle marking) is shown for comparison with the offshore ecotype (Fig. 2a,b). A total of 28-38 (based on size ranges tallied for each sighting) offshore individuals were documented. Photographs of sufficient quality to document identification/coloration marks were compared with those of coastal ecotypes from the sightings during crossings, as well as the long-term catalogue of over 300 resident coastal ecotype dolphins at the main study site in the Bahamas (Rogers et al., 2004). No obvious white saddle markings were evident in any of these coastal ecotype dolphins.

\section{False killer whale foraging}

At 1514 on May 24, 2006, 12 individually identifiable (through nicks, scars and shape of the dorsal fin) adult false killer whales were documented at $27^{\circ} 01^{\prime} 01^{\prime \prime} \mathrm{N}$, $79^{\circ} 15^{\prime} 24^{\prime \prime} \mathrm{W}$ (Fig. 3a). Most of the group remained at the surface, milling and surfacing slowly, while one or two animals dove. One of the diving animals returned to the surface with a large bloated fish (Fig. 3b). We could not get close enough to identify the species of the fish, however, it appeared to be a demersal species from the snapper or grouper family (Fig. 3c). The false killer whales at the surface then took turns biting chunks off the fish, and left only the gills. We observed three fish catch and consumption bouts within a two-hour observation period. We also observed social behavior occurring at the surface in-between feeding bouts, including two breaches and multiple spy-hops.

\section{Discussion}

All nine cetacean species documented in our study were also found in other western North Atlantic surveys (Kenney et al., 1997; Hamazaki, 2002; Schick et al., 2011). The NMFS stock assessments, as of 2014 , identified 30 cetacean species inhabiting the Western North Atlantic stock areas which include waters off the East Coast of the US (Waring et al., 2015). However, almost all the surveys that included waters off FL did not extend south of Central FL, and thus did not encompass our study area. Similarly, based on limited sighting data from OBIS-SEAMAP, 14 species were observed south of Cape Hatteras, though most sampling off the eastern FL coast was concentrated in Central and North FL waters (Schick et al., 2011). Based on the most current sighting data available in the OBIS-SEAMAP database, as of 2 


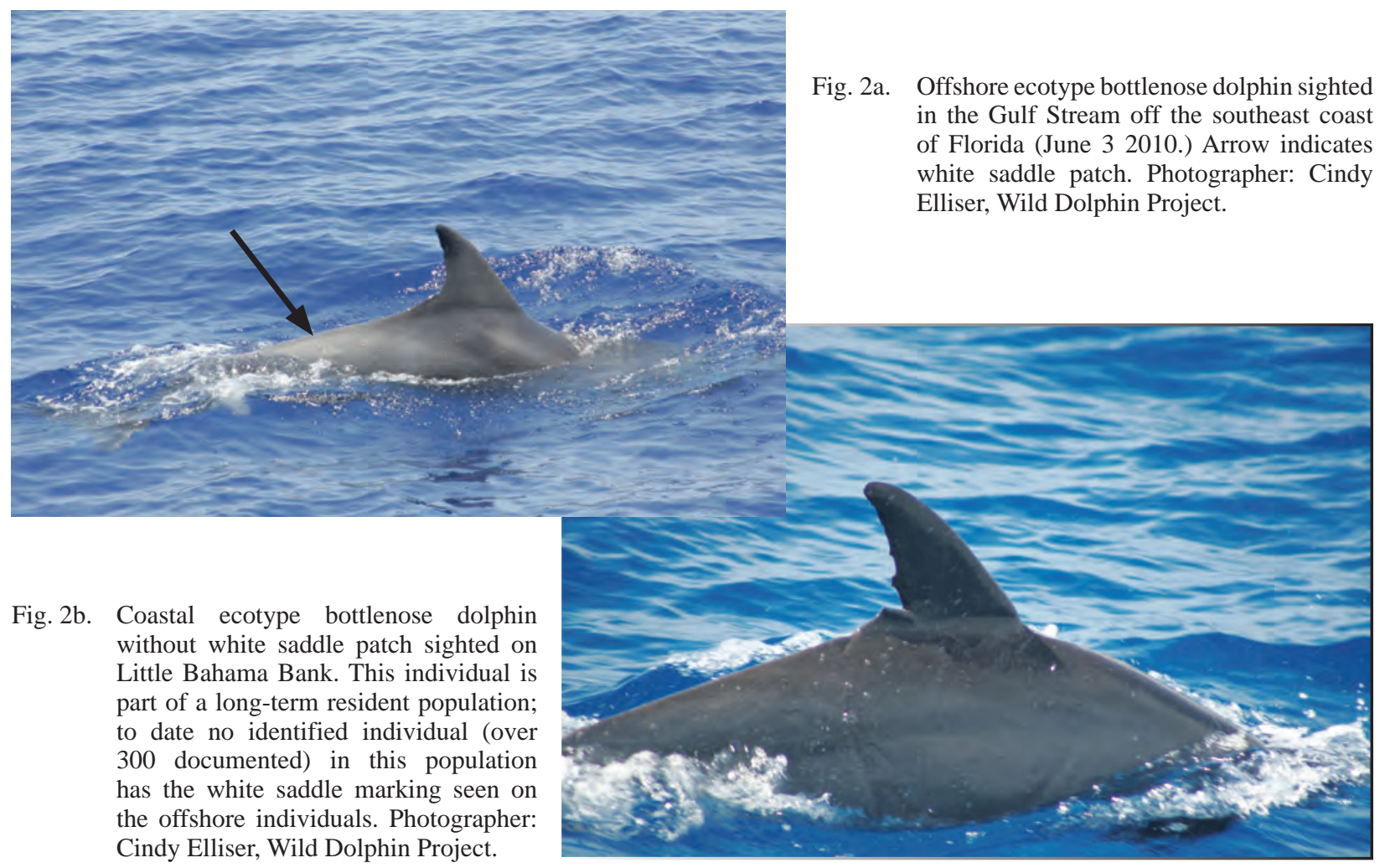

May 2016, only three of the nine species we observed have been documented by other research groups in our study area: the short-finned pilot whale (Dunn 2006; Halpin, 2009), sperm whale (Woolmer 2013; Halpin et al., 2009) and bottlenose dolphin (Garrison, 2013b; Josephson and Garrison, 2015a, 2015b). The other five species we observed (beaked whales were not considered for this comparison because we could not identify them to the species level) have only been seen to the north, east and/or south of our study area: Fraser's dolphin (Dunn, 2013b), false killer whale (Garrison, 2013a; Dunn, 2013b), pantropical spotted dolphin (Hyrenbach et al 2012; Dunn, 2013a; 2013b), Risso’s dolphins (Dunn, 2013b), and Atlantic spotted dolphin (Garrison, 2013c; Dunn, 2013a, 2013b; Josephson and Garrison, 2015b.). It is important to note that each of the nine species we observed have stocks designated by NMFS in both the western North Atlantic and the northern Gulf of Mexico, and that the individuals we observed off southeast FL may be from either or both of these regions. Our results indicate that the ranges of the nine species we observed may extend south of north/central FL, or may indicate movement from the Gulf of Mexico, at least seasonally. In addition, for the false killer whale, Fraser's dolphin, pantropical spotted dolphin, Risso's dolphin, Atlantic spotted dolphin and beaked whale, our sightings are the first known sightings in southeast FL waters. Thus, the opportunistic sightings we report here are a significant addition to the cetacean literature and the results reinforce that there is a need for more dedicated research efforts in our study area.

Two of the species we observed, the false killer whale and Fraser's dolphin, were rarely seen in Western North Atlantic surveys conducted north of central FL based on the most updated SARs for each species Waring et al, 2007, 2015). In previous SARs, a false killer whale stock (or stocks) was only designated for the Gulf of Mexico, but this information was updated in the 2014 SAR with an initial abundance estimate for a separate Western North Atlantic stock (Waring et al, 2015). The survey used for the abundance estimate was conducted during June-August, in 2011, but did not cover waters south of central FL. As of 2 May 2016, no live sightings of false killer whales have been reported in NMFS SARs (Waring et al., 2015) or in the OBIS-SEAMAP database (Halpin, 2009) within our study area, however, strandings have been documented during the winter (Caldwell et al., 1970). We observed false killer whales on four different occasions (1992, 1997, 2004 and 2006) during May-August. These data indicate that our study area serves as false killer whale habitat at least during the summer.

Sightings of Fraser's dolphin in the western North Atlantic are scarce (e.g. single sighting of 250 individuals from a 
1999 vessel survey off NC, which did not occur during the line-transect sampling effort), and thus population size and seasonal abundance are unknown for this stock, which is managed as a separate stock from that in the Gulf of Mexico (Waring et al., 2007). Although observed in all seasons in the more extensively surveyed northern Gulf of Mexico, they likely occur there in low numbers, but survey effort is not sufficient to precisely estimate their abundance (Waring et al., 2013). Data from OBIS-SEAMAP showed no sightings of Fraser's dolphins in our study area (Halpin, 2009), however, we documented two sightings during July of 1991 and 1993. Fraser's dolphins have also been documented as prey for killer whales (Orcinus orca) in the northern islands of the Bahamas, which is east of the Gulf Stream waters surveyed during our study (Dunn and Claridge, 2014). Thus, the sightings presented in our study represent the first reports of Fraser's dolphins in the western North Atlantic waters off southeast FL.

The sightings in our study primarily conform to the suggested distributions of deepwater versus coastal species (or ecotypes) in the Western North Atlantic where groupings of species tend to utilize particular habitats correlated with depth, temperature range and distance from the coast (Hamazaki, 2002; Schick et al., 2011). For the few discrepancies (refer to the "Bottlenose dolphins (coastal versus offshore ecotypes)" section below), however, we cannot determine whether the variations observed were outliers or indications of true habitat preferences, due to the opportunistic nature of our study.

\section{Bottlenose dolphins (coastal versus offshore ecotypes)}

Much of what is known about offshore ecotype bottlenose dolphins has been determined from stranded animals (e.g., Hersh and Duffield, 1990; Mead and Potter, 1995), which does not allow for description of their coloration patterns. The coastal and offshore ecotypes (treated as separate management units under the US Marine Mammal Protection Act of 1972) are described as genetically separable, partially sympatric, but visually indistinguishable (Waring et al., 2001; Torres et al., 2005). In our study, we were able to document bottlenose dolphins with white saddle markings on the peduncles of the larger, more robust individuals. This could be a useful marker for identifying the ecotypes at sea and through photographs. However, due to the opportunistic nature of our study, it is unknown if this trait is common to all individuals of the offshore ecotype or if it is limited solely to the offshore ecotype. It is also possible that this feature is limited to animals in our study area, because the study that documented differences in western North Atlantic ecotypes (Torres et al., 2003) did not include waters south of Central FL. More research combining morphological,

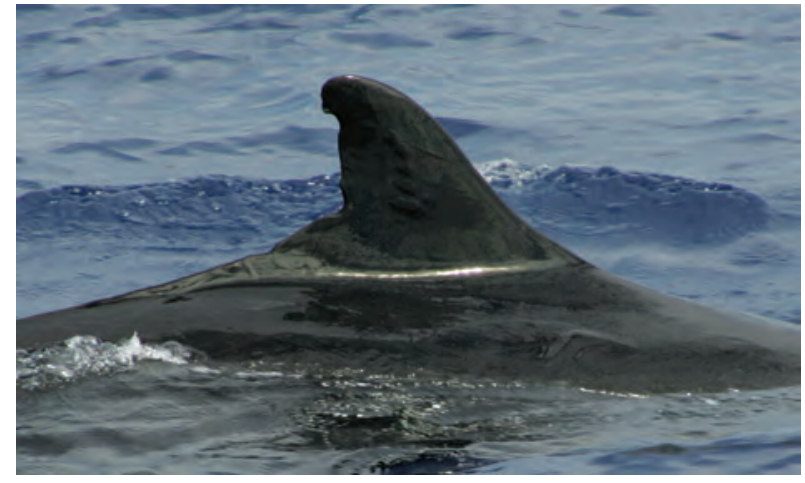

Fig. 3a. False killer whale dorsal fin. Twelve unique individuals were documented through nicks, notches and scars on the dorsal fins, such as seen here. Photographer: Cindy Elliser, Wild Dolphin Project.

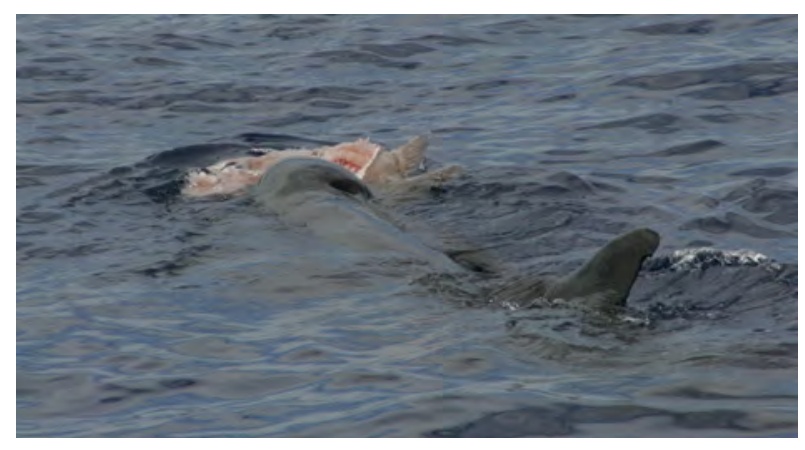

Fig. 3b. A false killer whale feeding on large, bloated demersal fish species brought to the surface. Photographer: Cindy Elliser, Wild Dolphin Project.

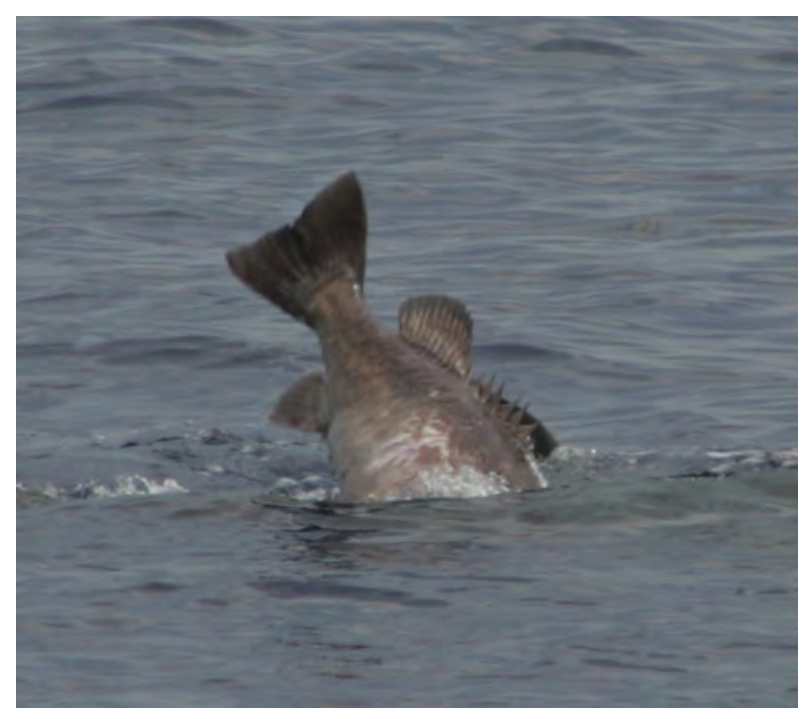

Fig. 3c. Large demersal fish species, from the Serranidae family, brought to the surface shortly before being eaten by false killer whales. Only the gills remained after feeding. Photographer: Cindy Elliser, Wild Dolphin Project. 
photographic, genetic and water depth data collected during quantitative surveys is needed to determine if this white saddle pigmentation is a reliable diagnostic marker for ecotype differentiation.

Individuals we identified as the offshore ecotype were found greater than $34 \mathrm{~km}$ from shore, except for one sighting that occurred $26 \mathrm{~km}$ from shore. Our results were similar to a study off Cape Hatteras, NC where Torres et al. (2003) determined that there was a differentiation regarding depth and distance from shore between the two ecotypes: dolphins found beyond $34 \mathrm{~km}$ from shore (and in waters deeper than $34 \mathrm{~m}$ ) were all of the offshore ecotype, whereas dolphins found within $7.5 \mathrm{~km}$ of shore were of the coastal ecotype. Torres et al. (2003) also found an overlap in the distributions of the two ecotypes, between 7.5 and $34 \mathrm{~km}$ from shore (and in waters less than $34 \mathrm{~m}$ deep), where both ecotypes were found, and identified this area as the "gray zone". It is known that the range of offshore bottlenose dolphins can extend (although in lower numbers) into the continental slope waters (Kenney, 1990). However, we cannot determine whether our sighting of offshore ecotype bottlenose dolphins at $26 \mathrm{~km}$ from shore (within the "gray zone") was due to an overlap in range with the coastal ecotype, because our sightings were not based on a quantitative survey. In addition, we used coloration patterns and Torres et al. (2003) used genetic analyses to distinguish between the two ecotypes. Furthermore, our method has not been verified quantitatively across region and ecotype. There is also the confounding fact of physiogeographic differences between the two study areas. In our study area, both deep water and the Gulf Stream occur closer to shore (the latter is often $<16 \mathrm{~km}$ from shore during summer) than is the case further north (Gyory et al., 2013). The distribution of both ecotypes may also be affected by the fact that our study area is bracketed by shallow water on both sides of the Gulf Stream (i.e., the FL shelf to the west and Little Bahama Bank to the east). Thus, further research regarding the distribution patterns and abundance of bottlenose dolphin ecotypes, as well as other cetacean species, are warranted in our study area.

Stock delineation of bottlenose dolphin populations along the US East Coast are complex and include estuarine stocks, five coastal stocks (Northern Migratory, Southern Migratory, South Carolina/Georgia Coastal, Northern Florida Coastal and Central Florida Coastal, (Waring et al., 2014) and one Western Atlantic Offshore stock (Waring et al., 2015). There has been little study of coastal stock structure south of central Florida and the southern boundary of the Central Florida stock is uncertain (Waring et al., 2014). The Offshore stock is based on surveys that do not extend south of central Florida (Waring et al.,
2014). Thus, information on stock structure in our study area is unknown, but it is clear that both ecotypes are present in southeast FL coastal and offshore waters, at least during the summer months (bottlenose dolphins were seen in every year from 1993-2005, except 2003, during May-September). In addition, there are multiple bottlenose dolphin stocks in the Northern Gulf of Mexico, including 31 bay, sound and estuarine stocks, the Gulf of Mexico Eastern Coastal stock, the Northern Gulf of Mexico Continental Shelf stock and the Northern Gulf of Mexico Oceanic stock (Waring et al., 2015). It is unclear whether the bottlenose dolphins observed in our study area should be considered as separate stocks or whether they are part of migratory or coastal stocks from the US East Coast and/or the Gulf of Mexico. Because many bottlenose dolphin stocks are migratory, it is important to understand the species' stock structure for management purposes, since movements of individuals or groups can involve intermingling between stocks and may vary with season. For example, off Cape Hatteras, $\mathrm{NC}$ there were definite seasonal changes in abundance and distribution of bottlenose dolphins. Abundance was greatest near shore $(<3 \mathrm{~km})$ during winter, but remained high out to $14 \mathrm{~km}$ (Torres et al., 2005). Combined with data from previous studies farther north, it is likely that the seasonal movement patterns along the US Atlantic coast are correlated, at least in part, with water temperature and prey availability (Torres et al., 2005). Similar results were found in the Gulf of Mexico for "Gulf" vs. "inshore" bottlenose dolphins, where "inshore" abundance increased and "Gulf" abundance decreased during the winter (Waring et al., 2015). Our opportunistic sightings reveal that more quantitative research is needed to determine the morphological and genetic characteristics of offshore bottlenose dolphins and for adequate stock management and conservation of both ecotypes in southeast FL waters.

\section{False killer whale foraging}

Most information about false killer whales, including prey, has been obtained from stranded animals in the Southern Hemisphere (Koen-Alonso et al., 1999; Andrade et al., 2001). Oceanic squid (e.g., Oregoniateuthis sp., Todarodes sp., Phasmatopsis sp., Gonatopsis borealis or Berryteuthis magister) have been documented as prey for false killer whales around the world (Stacey et al., 1994), and were the primary prey species found in Southern Hemisphere animals (Koen-Alonso et al., 1999; Andrade et al., 2001). Fish prey species included the Patagonian grenadier (Macruronus magellanicus), kingclip (Genypterus blacodes), as well as sciaenid species including whitemouth croaker (Micropogonias furnieri) and black drum (Pogonias cromis) (Koen-Alonso et al., 1999). The gut contents of some individuals included only 
fish contents from the families Sciaenidae and Serranidae based on otoliths (Pinedo and Rosas, 1989).

The false killer whales we sighted were feeding on what looked like a grouper. We contacted fish biologists at NOAA's Beaufort Laboratory and from the pictures they identified it as possibly Epinephelus sp., but definitely a serranid species (Jennifer Potts, pers. comm.). The group of false killer whales seemed to be sharing the prey and possibly feeding cooperatively. Cooperative feeding by false killer whales was suggested by KoenAlonso et al. (1999) due to the fact that the squid found in their stomachs usually form schools of restricted size range, indicating that the whales may have hunted cooperatively on the same schools. In Hawaiian waters, false killer whales prey mainly on large pelagic fish and are frequently observed sharing prey (Baird et al., 2008). Due to these facts and the species' tendency to carry prey items for extended periods, surface observations of prey items may be less biased than for other cetacean species (Baird et al., 2008). False killer whales can forage at depths up to 200 m (Koen-Alonso et al., 1999). Sighting rates for even the "island-associated" Hawaiian false killer whales, who regularly utilize shallow water $(<200 \mathrm{~m})$, reveal a preference for water deeper than 3,000 m (Baird et al., 2008). Although we do not have an exact depth for the foraging sighting in our study, it occurred at a depth greater than $200 \mathrm{~m}$. False killer whale ecology, abundance and distribution are unknown in our study area, however, it is evident that they do utilize local food resources and serranid fish species appear to be a part of their diet.

In conclusion, little is known about the cetaceans inhabiting the offshore waters of southeast FL. Through opportunistic sightings, we have documented nine cetacean species that inhabit the area during at least part of the year. Some of these species have very little existing information available regarding sightings and distribution in southeast FL waters. We have documented new information about the morphological features of offshore ecotype bottlenose dolphins, which may be useful in distinguishing between the two ecotypes at sea, and described the foraging behavior of false killer whales. This area of the Western North Atlantic has different physiogeographic and ecological features than areas farther north and our sightings demonstrate that the Gulf Stream is an important habitat for many cetacean species. Our observations highlight the need to conduct regular quantitative surveys of the offshore waters of southeast FL to better understand the distribution, abundance, stock boundaries and ecology of cetacean species in the area and how they relate to other populations along the US East Coast and in the Gulf of Mexico.

\section{Acknowledgements}

We thank the Wild Dolphin Project and all crew and volunteers involved during the time frame of this study. Thank you to Jennifer Potts, Michael Burton and Kenneth Brennan for helping with the fish identification. Reviews by Keith Mullin, Lisa Hendrickson and three anonymous reviewers improved the manuscript. This research was conducted under a permit from the Bahamian Department of Fisheries and NOAA permit LOC 13729-01.

\section{References}

ALTMANN, J. 1974. Observational study of behavior: Sampling methods. Behaviour, 49: 227-267.DOI: 10.1163/156853974X00534.

ANDRADE, A. L. V., M. C. PINEDO and A. S. BARRETO. 2001. Gastrointestinal parasites and prey items from a mass stranding of false killer whales, Pseudorca crassidens, in Rio Grande Do Sul, Southern Brazil. Rev. Bras. Biol., 61(1): 55-61. DOI: 10.1590/S0034-71082001000100008.

BAIRD, R. W., A. M. GORGONE, D. J. MCSWEENEY, D. L.WEBSTER, D. R. SALDEN, M. H. DEAKOS, D. LIGON, G. S. SCHORR, J. BARLOW and S. D. MAHAFFY. 2008. False killer Whales (Pseudorca crassidens) around the main Hawaiian Islands: long-term site fidelity, inter-island movements, and association patterns. Mar. Mammal Sci., 24(3): 591-612. DOI: 10.1111/j.1748-7692.2008.00200.x.

BYRD., B. L., C.A. HARMS, A. A. HOHN, W. A. MCLELLAN, G. N. LOVEWELL, K. T. MOORE, K. M. ALTMAN, P. E. ROSEL, S. G. BARCO, V. G. THAYER and A. FRIEDLAENDER. 2013. Strandings as indicators of marine mammal biodiversity and human interactions off the coast of North Carolina. Fish. Bull., 112(1):1-23. DOI: 10.7755/FB.112.1.1

CALDWELL, D. K., M. C. CALDWELL and C. M. WALKER, jr. 1970. Mass and individual strandings of false killer whales, Pseudorca crassidens, in Florida. J. Mammal., 51: 634-636. http://dx.doi.org/10.2307/1378415.

DUNN, C. 2006. Bahamas Marine Mammal Research Organisation Strandings. Data downloaded from OBISSEAMAP (http://seamap.env.duke.edu/dataset/327) on 2016-05-02.

2013a. Bahamas Marine Mammal Research Organisation On-transect Sightings. Data downloaded from OBISSEAMAP (http://seamap.env.duke.edu/dataset/328) on 2016-05-02.

2013b. Bahamas Marine Mammal Research Organisation Opportunistic Sightings. Data downloaded from OBISSEAMAP (http://seamap.env.duke.edu/dataset/329) on 2016-05-02.

DUNN, C. A. and D. E. CLARIDGE. 2014. Killer Whale (Orcinus orca) occurrence and predation in the Bahamas. $J$. Mar. Biol. Assoc. U. K., 94(6): 1305-1309. DOI: 10.1017/ S0025315413000908.

ELLISER, C. R. and D. L. HERZING. 2012. Community structure and cluster definition of Atlantic spotted dolphins, 
Stenella frontalis, in the Bahamas. Mar. Mammal Sci., 28(4): E486-E502. DOI: 10.1111/j.1748-7692.2012.00576.x.

2014. Long-term social structure of a resident community of Atlantic spotted dolphins, Stenella frontalis, in the Bahamas 1991-2002. Mar. Mammal Sci., 30(1): 308-328. DOI: $10.1111 / \mathrm{mms} .12039$.

GARRISON, L. 2013a. SEFSC Atlantic surveys 1992. Data downloaded from OBIS-SEAMAP (http://seamap.env. duke.edu/dataset/3) on 2016-05-02.

2013b. SEFSC Atlantic surveys, 1998 (3). Data downloaded from OBIS-SEAMAP (http://seamap.env. duke.edu/dataset/1) on 2016-05-02.

2013c. SEFSC Southeast Cetacean Aerial Survey 1992. Data downloaded from OBIS-SEAMAP (http://seamap.env. duke.edu/dataset/87) on 2016-05-02.

GARRISON, L. P., A. MARTINEZ and K. MAZE-FOLEY. 2010. Habitat and abundance of cetaceans in Atlantic Ocean continental slope waters off the eastern USA.J. Cetacean. Res. Manage., 11(3): 267-277.

GROVES, D. G. and L. M. HUNT. 1980. The Ocean World Encyclopedia. McGraw-Hill, New York.

GYORY, J., E. ROWE, A. J. MARIANO and E. H. RYAN, 2013 “The Florida Current.” Ocean Surface Currents. http://oceancurrents.rsmas.miami.edu/atlantic/florida.html. Downloaded 2016-05-02

HALPIN, P. N., A. J. READ, E. FUJIOKA, B. D. BEST, B. DONNELLY, L. J. HAZEN, C. KOT, K. URIAN, E. LABRECQUE, A. DIMATTEO, J. CLEARY, C. GOOD, L.B. CROWDER, and K. D. HYRENBACH. 2009. OBISSEAMAP: the world data center for marine mammal, sea bird and sea turtle distributions. Oceanog., 22(2): 104-115. DOI: 10.5670/oceanog.2009.42.

HAMAZAKI, T. 2002. Spatiotemporal prediction models of cetacean habitats in the mid- Western North Atlantic ocean (from Cape Hatteras, North Carolina, U.S.A. to Nova Scotia, Canada). Mar. Mammal Sci., 18(4): 920-939. DOI: 10.1111/j.1748-7692.2002.tb01082.x.

HERSH, S. L and D. A. DUFFIELD. 1990. Distinction between northwest Atlantic Offshore and coastal bottlenose dolphins based on hemoglobin profile and morphometry. In: The Bottlenose Dolphin. S. Leatherwood and R.R. Reeves (eds.) New York, NY: Academic Press, p. 129-139.

HERZING, D. L. 1997. The life history of free-ranging Atlantic spotted dolphins (Stenella frontalis) age classes, color phases and female reproduction. Mar. Mammal Sci., 13(4): 576-595. DOI: 10.1111/j.1748-7692.1997.tb00085.x.

HOELZEL, A. R., C. W. POTTER and P. B. BEST. 1998. Genetic differentiation between parapatric 'nearshore' and 'offshore' populations of the bottlenose dolphin. Proc. R. Soc. London, Ser. B, 265: 1177-1183. DOI: 10.1098/ rspb.1998.0416.

HOFFMAN, W. and T. H. FRITTS. 1982. Sea turtle distribution along the boundary of the Gulf Stream current off eastern Florida. Herpetologica 38(3): 405-409.

HYRENBACH, D., F. HUETTMANN and J. CHARDINE. 2012. PIROP Northwest Atlantic 1965-1992. Data downloaded from OBIS-SEAMAP (http://seamap.env. duke.edu/dataset/280) on 2016-05-02.
JEFFERSON, T. A. and A. J. SCHIRO. 2008. Distribution of cetaceans in the offshore Gulf Of Mexico. Mammal Rev., 27(1): 27-50. DOI: 10.1111/j.1365-2907.1997.tb00371.x.

JOSEPHSON, B. and L. GARRISON. 2015a. AMAPPS Southeast Aerial Cruise Summer 2011. Data downloaded from OBIS-SEAMAP (http://seamap.env.duke.edu/ dataset/1275) on 2016-05-02.

2015b. AMAPPS Southeast Aerial Cruise Spring 2012. Data downloaded from OBIS-SEAMAP (http://seamap. env.duke.edu/dataset/1259) on 2016-05-02.

KENNEY, R. 1990. Bottlenose Dolphins off the Northeastern United States. In: The Bottlenose Dolphin. S .Leatherwood and R. Reeves (eds.). San Diego: Academic Press, p. 369-386.

KENNEY, R. D., G. P. SCOTT, T. J. THOMPSON and H. E. WINN. 1997. Estimates of prey consumption and trophic impacts of cetaceans in the USA Northeast continental shelf ecosystem. J. Northwest. Atl. Fish. Sci., 22: 155-171. DOI: 10.2960/J.v22.a13

KOEN-ALONSO, M., S. N. PEDRAZA, A. C. M. SCHIAVINI, R. N. P. GOODALL and E. A. CRESPO. 1999. Stomach contents of false killer whales (Pseudorca crassidens) stranded on the coasts of the Strait of Magellan, Tierra del Fuego. Mar. Mammal Sci., 15(3): 712-724. DOI: 10.1111/j.1748-7692.1999.tb00838.x.

MAZE-FOLEY, K. and K. D. MULLIN. 2006. Cetaceans of the oceanic northern Gulf of Mexico: Distributions, group sizes and interspecific associations. J. Cetacean Res. Manage., 8(2): 203-213.

MEAD, J. G. and C. W. POTTER. 1995. Recognizing two populations of the bottlenose dolphin (Tursiops truncatus) off the Atlantic coast of North America: morphological and ecological considerations. IBI reports, No. 5: 31-44.

MOORE, J. C. 1953. Distribution of marine mammals to Florida waters. Am. Midl. Nat. 49(1): 117-158.

MULLIN, K. D. and G. L. FULLING. 2003. Abundance and distribution of cetaceans in the southern U.S. Atlantic Ocean during summer 1998. Fish. Bull. 101: 603-613.

2004. Abundance of cetaceans in the oceanic Northern Gulf of Mexico, 1996-2001. Mar. Mammal Sci., 20(4): 787-807. DOI: 10.1111/j.1748-7692.2004.tb01193.x.

NOAA [National Oceanic and Atmospheric Administration] 2012, Southeast Region Marine Mammal \& Sea Turtle Viewing Guidelines http://www.nmfs.noaa.gov/pr/ education/southeast/. Accessed 2016-05-02

OWEN, R. W. 1981. Fronts and eddies in the sea: mechanisms, interactions and biological effects. In: Analysis of marine ecosystems. A. R. Longhurst (ed.) New York: Academic Press, p. 197-233.

PINEDO, M. C. and F. C. W. ROSAS. 1989. Novas ocorrências de Pseudorca crassidens (Cetacea: Delphinidae) para o Atlântico Sul Ocidental, com observações sobre medidas cranianase alimentação. Atlântica, 11(1): 73-83.

POTTS, JENNIFER. Pers. Comm. April 2016. Research Fishery Biologist, Sustainable Fisheries Branch, National Marine Fisheries Service.

ROGERS, C. A., B. J. BRUNNICK, D. L. HERZING and J. D. BALDWIN. 2004. The social structure of bottlenose 
dolphins, Tursiops truncatus, in the Bahamas. Mar. Mammal Sci., 20(4): 688-708. DOI: 10.1111/j.17487692.2004.tb01188.x.

RONE, K. B. and R. M. PACE III. 2012. A simple photographbased approach for discriminating between free-ranging long-finned (Globicephala melas) and short-finned (G. macrorhynchus) pilot whales off the east coast of the United States. Mar. Mammal Sci., 28(2): 254-275. DOI: 10.1111/j.1748-7692.2011.00488.x.

SCHICK, R. S., P. N. HALPIN, A. J. READ, D. L. URBAN, B. D. BEST, C. P. GOOD, J. J. ROBERTS, E. A. LABRECQUE, C. DUNN, L. P. GARRISON, K. D. HYRENBACH, W. A. MCLELLAN., D. A. PABST, D. L. PALKA and P. STEVICK. 2011. Community structure in pelagic marine mammals at large spatial scales. Mar. Ecol.:Prog. Ser., 434: 165-181. DOI:10.3354/meps09183.

STACEY, P. J., S. LEATHERWOOD and R. W. BAIRD. 1994. Pseudorca crassidens. Mamm. Species, 456: 1-6. DOI: $10.2307 / 3504208$.

TORRES, L. G., P.E ROSEL, C. D’AGROSA and A. J. READ. 2003. Improving management of overlapping bottlenose dolphin ecotypes through spatial analysis and genetics. Mar. Mammal Sci. 19(3): 502-514. DOI: 10.1111/j.17487692.2003.tb01317.x

TORRES, L. G., W. A. MCLELLAN, E. MEAGHER and D. A. PABST. 2005. Seasonal distribution and relative abundance of bottlenose dolphins, Tursiops truncatus, along the US mid-
Atlantic Coast. J. Cetacean Res. Manage. 7(2): 153-161. WARING, G. T., C. P. FAIRFIELD, C. M. RUHSAM, and M. SANO. 1993. Sperm whales associated with Gulf Stream features off the north-eastern USA shelf. Fish. Oceanog. 2(2): 101-105. DOI: 10.1111/j.1365-2419.1993.tb00126.x

WARING, G. T., J. M. QUINTAL AND S. I. SWARTZ. 2001. U.S. Atlantic and Gulf of Mexico marine mammal stock assessments - 2001. U.S. Department of Commerce. NOAA Tech. Memo. NMFS NE 168, 307 p.

WARING G. T., E. JOSEPHSON, C. P. FAIRFIELD-WALSH, K. MAZE-FOLEY, editors. 2007. U.S. Atlantic and Gulf of Mexico Marine Mammal Stock Assessments — 2007. NOAA Tech Memo NMFS NE 205, 415 p.

WARING G. T., E. JOSEPHSON, K. MAZE-FOLEY, P. E. ROSEL, editors. 2013. U.S. Atlantic and Gulf of Mexico Marine Mammal Stock Assessments — 2012. NOAA Tech Memo NMFS NE 223, 419 p.

2014. U.S. Atlantic and Gulf of Mexico Marine Mammal Stock Assessments - 2013. NOAA Tech Memo NMFS NE 228, 464 p

2015. US Atlantic and Gulf of Mexico Marine Mammal Stock Assessments — 2014. NOAA Tech Memo NMFS NE 231, 361 p. DOI: 10.7289/V5TQ5ZH0

WOOLMER, G. 2013. Historical distribution of whales shown by logbook records 1785-1913. Data downloaded from OBIS-SEAMAP (http://seamap.env.duke.edu/dataset/885) on 2016-05-02. 
